\title{
SEDIMENTOLOGICAL AND GEOCHEMICAL CHARACTERIZATION OF HOLOCENE SEDIMENTS, FROM ALIKES LAGOON, ZAKYNTHOS ISLAND, WESTERN GREECE
}

\author{
Avramidis P. ${ }^{1}$, Panagiotaras D. ${ }^{2}$, Papoulis D. ${ }^{3}$, Kontopoulos N. ${ }^{3}$ \\ ${ }^{1}$ Technological Educational Institute of Mesolonghi, Laboratory of Geology of Aquatic Systems, \\ 30200 Mesolonghi, Greece \\ ${ }^{2}$ Technological Educational Institute of Patras, Department of Mechanical Engineering, \\ 26334 Patras, Greece \\ ${ }^{3}$ University of Patras, Department of Geology, 26500 Patras, Greece
}

\begin{abstract}
The study area is the Alikes wetland (an old salt pan) which is located in the northern part of Zakynthos island. In the Alikes lagoon an exploratory borehole (GA-1) were drilled in a depth up to $21.20 \mathrm{~m}$. A total number of forty six (46) samples were analysed for their particle size, calcium carbonate and total organic carbon content. Moreover, bulk sample chemical analyses for major and trace elements were carried out on 12 samples, as well as mineralogical analysis for bulk, oriented and the clay fraction $(<2 \mu \mathrm{m})$ were determined by powder X-Ray diffraction. The grain size characteristics, statistical parameters and TOC, for the Holocene analysed samples, suggest a coastal environment (restricted-shallow) with reduced salinity such as a lagoon margin and in a tidal flat and/or marsh particularly. Depositional environments and the source material affecting the geochemical signature indicating that that $\mathrm{Al}, \mathrm{Mg}, \mathrm{K}$ are mainly associated with the aluminosilicate fraction of the sediments analyzed, Fe and Ti consistent with detrital phases, while Ca, Si, P, and Mn showing different geochemical patterns.
\end{abstract}

Key words: sedimentology, geochemistry, Holocene sediments, Alikes, Zakynthos.

\section{Introduction}

There are different approaches in reconstruction the Holocene coastal - lagoon environmental changes, which are based on geological, geochronological, sedimentological and geochemical analyses methods. Studies in western Greece, investigating and reviewing the Holocene environmental changes in coastal lagoonal areas, have been carried out by Kontopoulos and Avramidis (2003), Kraft et al. (2005), Vött (2007), Avramidis et al. (2008), Kontopoulos and Koutsios (2009), Avramidis \& Kontopoulos (2009) and Engel et al. (2009).

Geological processes that affect the chemical composition of sediments include hydraulic sorting, weathering and diagenesis (Fralick and Kronberg, 1997). Significant improvement has been made in geochemical approaches to monitoring sediment provenance, especially through the introduction of discrimination diagrams based on the relationship of major and trace elements (Condie, 1993; Cullers, 1994; Bauluz et al., 2000). Whilst trace element geochemical studies have tended to focus on aspects of sediment provenance, their application to paleoclimate reconstructions has been rela- 


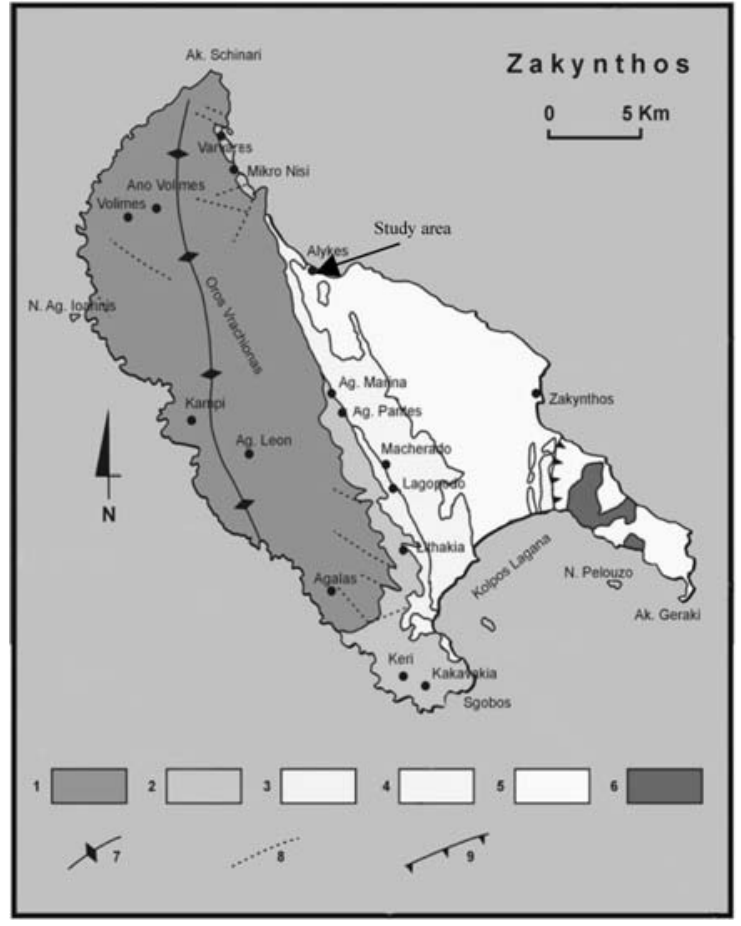

Fig. 1: Simplified geological map of Zakynthos Island. Legend: 1. Cretaceous carbonates, 2. Eocene carbonates, 3. Oligocene marly carbonates, 4 . Miocene clastics and carbonates, 5. Pliocene-Quaternary alluvial deposits, 6. Ionian evaporites and breccias, 7. Anticline, 8. Fault, 9. Main thrust.

tively neglected, with most paleoclimate studies focusing on biogenic components, such as carbonate, opal, organic carbon and authigenic elements (Elderfield, 1990). On the other hand, the geochemical behaviour of trace elements in natural systems may often reflect changes in the chemical, biological, and physical conditions of the environment. For example, Mn and Fe change their chemical forms and concentrations according to the redox condition (Stumm and Morgan 1996), while distribution profiles of some bio-elements such as $\mathrm{Ca}, \mathrm{P}$ and $\mathrm{Si}$, are sensitively affected by biological activity (Riley and Chester 1983).

The purpose of the present paper is to study the Holocene sedimentological environments of the Alikes lagoon, Zakynthos island (Fig. 1) as well as the geochemical and mineralogical changes, based on a $21.2 \mathrm{~m}$ sediment core. An effort is made to record the Holocene palaeonvironmental evolution - changes of the area and to correlate them with the sediment geochemical and mineralogical distribution.

\section{Geological setting}

The study area is the Alikes wetland (an old salt pan) which is located on the northern part of Zakynthos island (Fig. 1), and expand in an area of $400.000 \mathrm{~m}^{2}$. The Zakynthos island is characterised by two geotectonic zones the Pre-Apulian and the Ionian zone. It is located near the north-western terminus of the Hellenic Trench, very close to the convergent boundary between the African and European plates and the diapirism area of the evaporates, that belong to the Alpine basement. The sedimentological evolution of the island was influenced by both compresional and extensional tectonics (Zelilidis et al,. 1998) while sedimentation can be distinguished in carbonates Cretaceous to Miocene and clastic Plio - Quaternary (Fig. 1). 


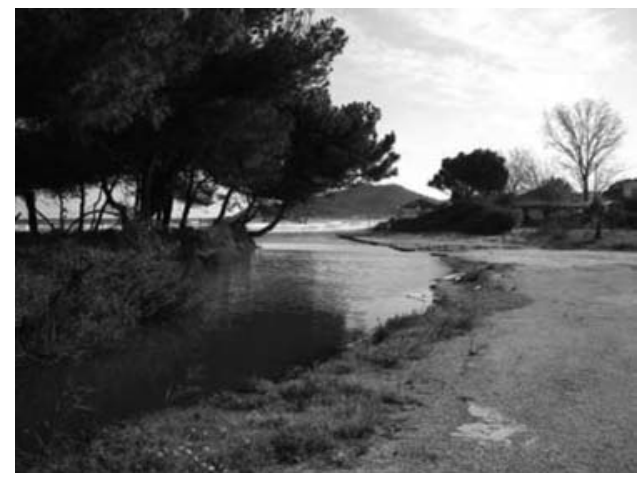

Fig. 2: The narrow inlet in the northern part of the lagoon.

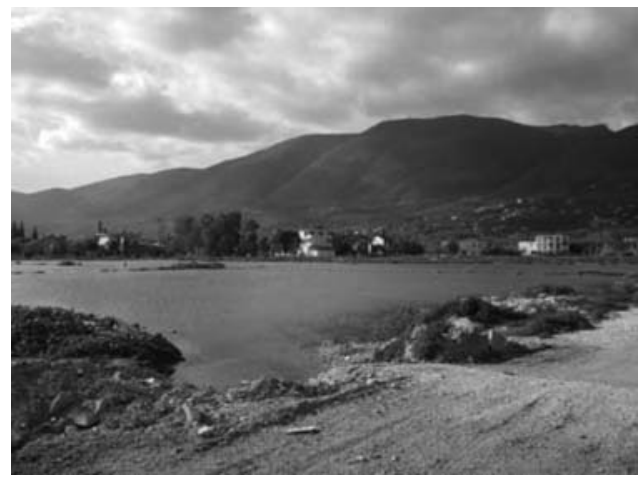

Fig. 3: General view of the lagoon with maximum depth up to $45 \mathrm{~cm}$.

In the study area, Alikes lagoon, during the last decades human activities such as agriculture, irrigation works and building development influenced, the water surface of the lagoon. On the northwest side, the Alikes lagoon is separated from the Ionian Sea by a low relief sand barier and has limited communication with the open sea with a sort and narrow inlet (Fig. 2). The maximum water depth of the lagoon is up to $45 \mathrm{~cm}$ and an average depth only up to $15 \mathrm{~cm}$ (Fig. 3). Holocene sedimentation rates for Alikes lagoon area have been estimated by Avramidis \& Kontopoulos (2009) and reveal two different stages of sedimentation rate: the first one between $8280 \mathrm{BP}$ and $5590 \mathrm{BP}$ $(5.3 \mathrm{~mm} / \mathrm{yr})$ and the second one between $5590 \mathrm{BP}$ and modern times $(1.03 \mathrm{~mm} / \mathrm{yr})$.

\section{Methods}

The exploratory core GA-1 (Fig. 4) was bored in February 2008, at the geographical position N $37^{0} 50^{\prime} 32^{\prime \prime}$, E $20^{\circ} 45^{\prime} 51^{\prime \prime}$. The drilling equipment was a rotation Longyear 38, with single tube core barrel with tungsten carbide bit and $101 \mathrm{~mm}$ diameter. All the segments of the core were sealed with cling film. Sediment types, structure, colour, as well as contact depths and bed characteristics, were recorded. Colour were identified using a Minolta CM-2002 hand held spectrophotometer. Standarised sedimentological analysis were carried out, on 46 samples including particle size analysis, calcium carbonate and organic carbon content. Particle size distribution was made using a Malvern Mastersizer 2000, while moment measures were calculated using GRADISTAT V.4 and based on Folk (1974) nomenclature. The organic carbon content was estimated by the titration method according to Gaudette et al. (1974).

Bulk sample chemical analyses for major and trace elements were carried out on 12 samples at the Activation Laboratories and were performed using a Thermo Jarrell-Ash ENVIRO II ICP for INAA and a Perkin Elmer Optima 3000 ICP. Silica, $\mathrm{SiO}_{2}$ was determined using the X-ray Fluorescence method after $\mathrm{LiBO}_{2}$ fusion and $\mathrm{Zr}$ was measured by the xylenol orange colorimetric method (Roser et al., 2000).

The mineralogical composition of bulk samples and of the clay fraction $(<2 \mu \mathrm{m})$ separated by sedimentation was made on 12 samples and were determined by powder X-Ray diffraction (XRD), using a Bruker D8 advance diffractometer, with Ni-filtered $\mathrm{CuK} \alpha$ radiation. Powders from oriented samples were prepared by the dropper method and were scanned at $1^{\circ} 2 \theta /$ min from 3 to $70^{\circ} 2 \theta$. Random powder mounts were prepared by gently pressing the powder into the cavity holder. For each $<2 \mu \mathrm{m}$ specimen, the clay minerals were identified from three XRD patterns (after air-drying at $25^{\circ} \mathrm{C}$ ). 


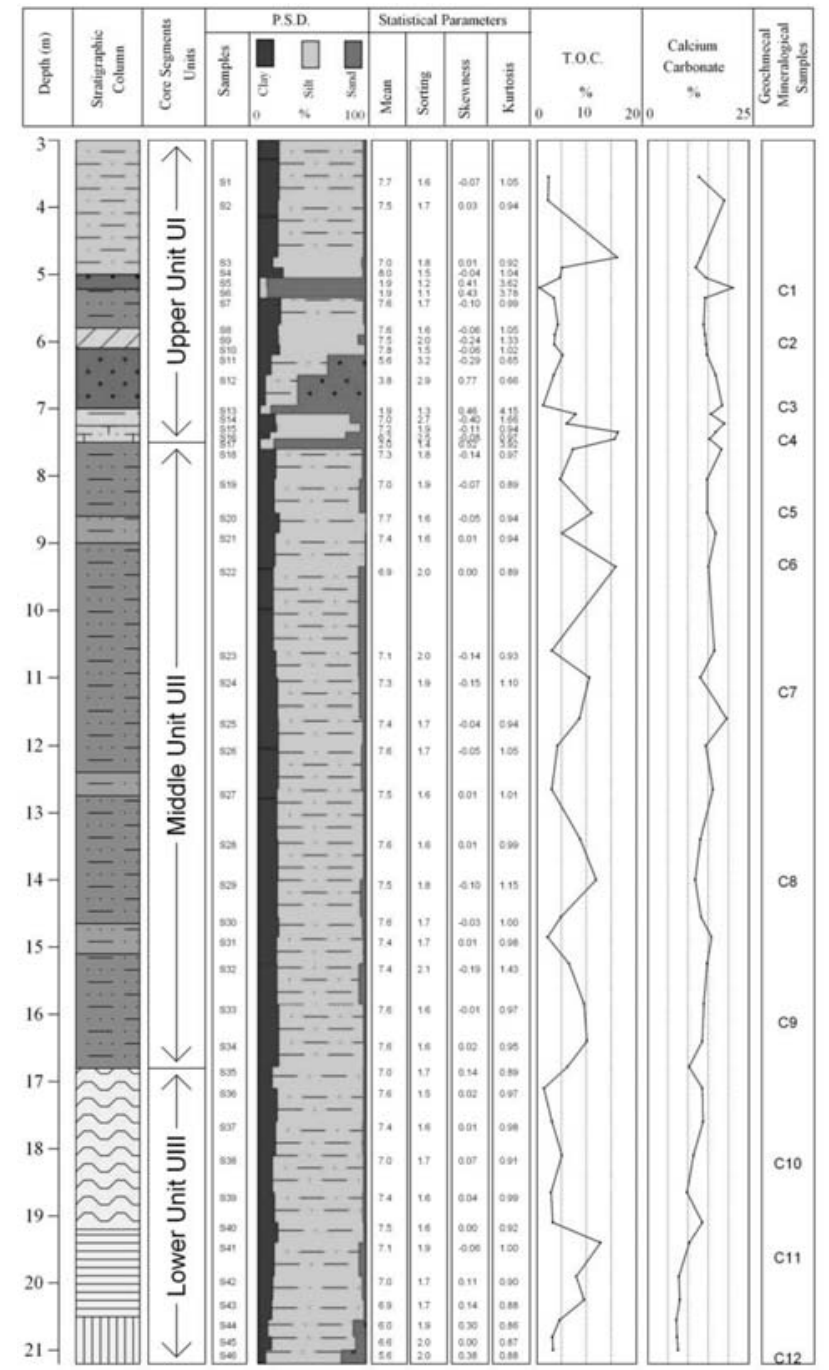

Fig. 4: Borehole profile GA-1 modified after Avramidis \& Kontopoulos (2009), showing the sedimentary units, the P.S.D. - statistical parameters, TOC, carbonate content and geochemical - mineralogical analyzed samples.

\section{Results}

\subsection{Sedimentology}

The sedimentological core description is based on Avramidis \& Kontopoulos (2009) discrimination of three major sedimentary units. The upper unit UI (3.00-7.50m), middle UII $(7.50-16.80 \mathrm{~m})$ and lower UIII (16.80-21.20 m) (Fig. 4).

Upper Unit (3.00-7.50 m): refer to the upper part of the core segment between depth $3.00 \mathrm{~m}$ to $7.50 \mathrm{~m}$ (Fig. 6), we didn't take into account material between depths $0.00-3.00 \mathrm{~m}$ as it is classified as filling material (pave) for road construction. The unit consist of poorly to very poorly sorted, grayish olive, laminated fine to medium silt, rich in organic matter with bioturbation structures and shell fragments. Silt 
is intercalated by three main horizons of poorly sorted, olive brown to dark olive, fine to medium sand $(5.00-5.22 \mathrm{~m}, 6.00-7.00 \mathrm{~m}$ and $7.25-7.50 \mathrm{~m})$. Contacts between silt and sand are characterised as slightly erosional. The sand fraction consists of foraminifera, ostracodes and molluscs 15 in proportion less than $2 \%$ to the clastic grains. Also, there are carbonate - cementing aggregates in abundance in the sand fraction. The calcium carbonate content in the upper unit ranges from 11.90 to $21.00 \%$ with an average value $13,07 \%$, while TOC between 0.54 to $16.30 \%$ with an average value $5.36 \%$ (Fig. 4).

Middle Unit (7.50-16.80 m): consist of poorly sorted, very dark greenish gray fine silt, with shell fragments, thin layers rich in organic matter with plant remains and abundant shell fragments and 20 Cardium shells. The sand fraction contains mostly micro- and macrofossils and abundance plant remains. Caliche-like evaporate, largely of a calcium carbonate type, is found cementing some of the grain together into aggregates. Internally to this unit we distinguish three layers (8.60-9.00 m, $12.40-12.60 \mathrm{~m}$ and $14.65-15.10 \mathrm{~m}$ ) consisting of poorly sorted grayish olive fine silt and is characterised by ripple lamination. The calcium carbonate content in the middle unit ranges from 11.71 to $19.48 \%$ with an average value $14,97 \%$, while TOC between 2.16 to $15.79 \%$ with an average value $7.90 \%$ (Fig. 4).

Lower Unit (16.80-21.20 m): consist of poorly sorted, greenish gray fine to coarse silt. This unit is characterized by the presence of Cardium, Cerithium and Hydrobia, Ammonia shells and abundant organic matter. Also, there are carbonate-cementing aggregates in abundance in thesand fraction. In the lower part of the unit we observe an increase in sand participation and we distinguish a layer of poorly sorted, light olive gray to grayish olive, coarse silt. The calcium carbonate content in the lower unit ranges from 7.09 to $13.65 \%$ with an average value $9.94 \%$, while TOC between 1.4 to $12.81 \%$ with an average value $5.23 \%$ (Fig. 4 ).

\subsection{Geochemical analysis}

Results of chemical analysis for the sediments collected from the Alikes Lagoon, are summarized in Table 1. The $\mathrm{SiO}_{2}$ contents of the samples range from 37.92 to $64.02 \mathrm{wt} . \%$ and are enriched relative to Clay Shales (CSH). The $\mathrm{Al}_{2} \mathrm{O}_{3}$ contents of the samples are higher than of CSH (8 wt.\%), except of the samples with codes $\mathrm{C} 2$ and $\mathrm{C} 5$. By contrast, the $\mathrm{CaO}$ contents are remarkably higher than that of $\mathrm{CSH}(2,20 \mathrm{wt} . \%)$. Most samples show that the $\mathrm{Na}_{2} \mathrm{O}$ contents are enriched relative to $\mathrm{CSH}$, while $\mathrm{K}_{2} \mathrm{O}$ contents shown slightly lower values relative to $\mathrm{CSH}$, with their average values being of $1.70 \mathrm{wt} . \%$ and $2.13 \mathrm{wt} . \%$ respectively. $\mathrm{MgO}$ contents of the samples range from 0,92 to 4,49 wt. $\%$, with their average value being higher $(3,42 \mathrm{wt} . \%)$ than the $\mathrm{CSH}(1,50 \mathrm{wt} . \%)$. The $\mathrm{Fe}_{2} \mathrm{O}_{3}$ concentrations are slightly higher than the $\mathrm{CSH}$ values, with the samples $\mathrm{C} 2, \mathrm{C} 4, \mathrm{C} 5$ and $\mathrm{C} 12$ showing lower concentrations than $\mathrm{CSH}$. The $\mathrm{MnO}$ content of the samples ranges from 0.043 to $0.112 \mathrm{wt} \%$, while $\mathrm{TiO}_{2}$ concentrations range from 0.08 to $0.686 \mathrm{wt} . \%$ being in the same magnitude with the $\mathrm{CSH}$ values. The $\mathrm{P}_{2} \mathrm{O}_{5}$ contents of the samples are enriched compare to the CSH concentration, with their average value being 0,089 wt. $\%$. The LOI (Lost Of Ignition) values ranges from 9,89 to 21,21 wt. $\%$ with an average value of $17,98 \mathrm{wt} . \%$.

\subsection{Mineralogical analysis}

The mineralogical composition of samples C1-C5 is characterized by the dominant presence of quartz, calcite, albite, chlorite and illite, while lepidocrocite presence was detected in samples $\mathrm{C} 4$, C5 (Fig. 5). The sample C6 shows a different mineralogical composition and halite and gypsum coexist with calcite, albite, chlorite, quartz and illite (Fig. 5). Samples C7-C12 are characterized by the dominance of illite and the presence of quartz, albite, chlorite and calcite and traces of lepidocrocite. 
Table 1. Results of chemical analysis for the sediments collected from the Alikes Lagoon borehole GA-1.

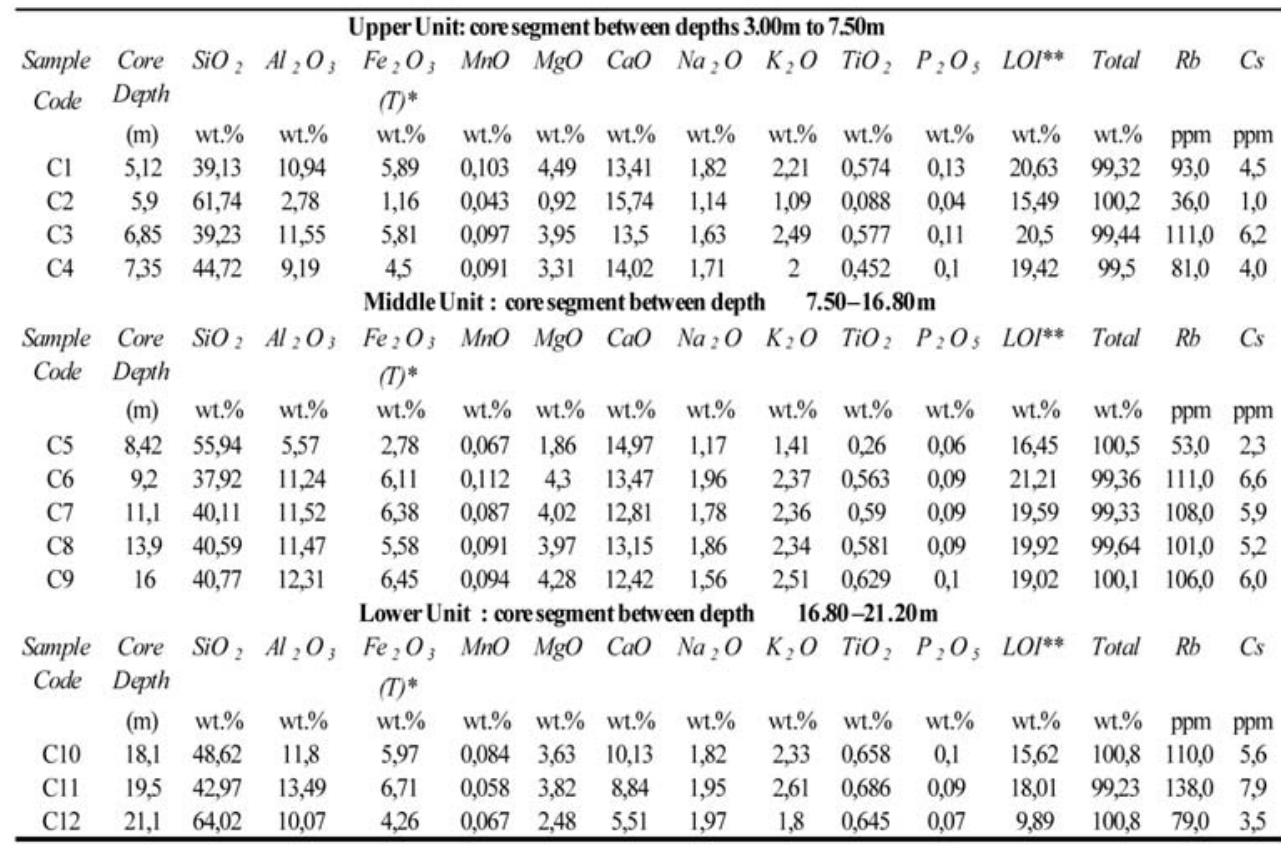

* (T): Total, **LOI: Lost of Ignition

Increasing depth the amount of chlorite as well as calcite is decreasing while illite is increasing. Vermiculite is present in samples C9-C12 (Fig. 5).

\section{Discussion}

The particle size distribution throughout the core indicate a relative uniform distribution of grain size. Sediment types are fine to coarse silt with three intercalations of medium sand in the upper unit. The presence of sand is low, ranging between 0 to 5\%, clay percent ranges between 2 to $20 \%$ and silt between 69 to $85 \%$ (Fig. 4). Almost all the analysed sediments are characterised as poor to very rich in organic matter $(\mathrm{TOC}>0.5)$, while carbonate content participate in a portion $>8 \%$.

Based on statistical parameters, in the upper core segment, the silt material is characterised as poorly to very poorly sorted, while skewness indicate basically a symmetrical distribution and values of kurtosis propose a mesokurtic distribution. The sand layers of the upper unit appear to be poorly to very poorly sorted while skewness in all sand samples indicate very fine skewed distribution while kurtosis propose mainly an extremely leptokurtic distribution. The very fine skewed value is caused by the presence of a fine tail in the sand-dominate size frequency curve. This fine tail in combination with the poorly to very poorly sorting and extremely leptokurtic kurtosis may be suggesting an event analogous with a fluvial flood. This event may occur in a coastal environment such as a sandy tidal flood. If this happens then the silt beds of this unit which have a very low sand content, poorly to very poorly sorting and normal distribution, have deposited in a sheltered muddy tidal flat or marshy area. The middle unit indicate a uniform distribution of poorly sorted fine silt while skewness and kurtosis in- 


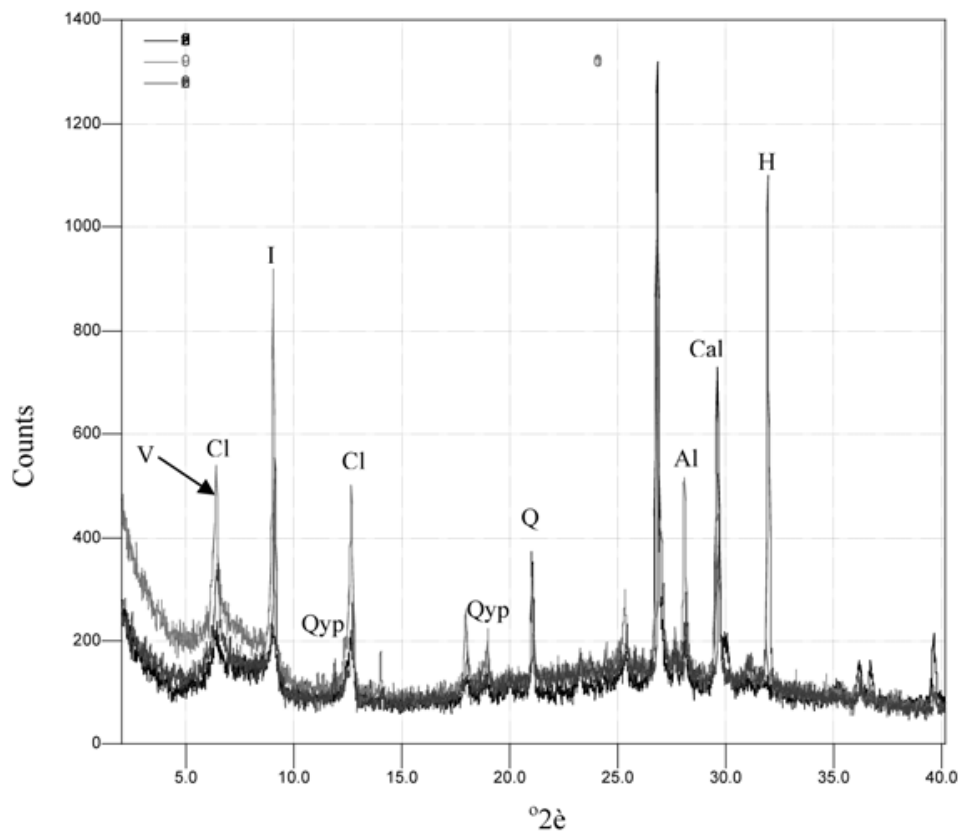

Fig. 5: X-ray diffraction patterns of representative oriented samples C3, C6, C10. Cl:Chlorite, I:illite, Qyp: Gypsum, Q: quartz, Al:Albite, H: Halite.

dicate mainly a symmetrical and mesokurtic distribution. The participation of sand is very low $<5 \%$ (Fig. 4). These grain size statistical parameters are the same as those of the silt beds of the upper unit. This event and the very low sand content suggest also a sheltered muddy tidal flat or marshy area. The lower unit of the core is characterized by poorly sorted fine to medium silt and the increase of the sand participation in the lower part, depth 20.55-21.20 m, where we have the presence of coarse silt. Participation of sand is low $<7 \%$ with exception the lower part of the unit where increases up to $23 \%$. Skewness present a symmetrical to fine skewed distribution, while kurtosis a mesokurtic one. According to the grain size statistical parameters the mainly part of the unit III has deposited also in a sheltered muddy tidal flat or marshy area. The lower part of the unit III where the sand content increases, the skewness is near symmetrical to fine skewed and the kurtosis is slight platykurtic, may have deposited in a mixed flat environment.

However geochemical analyses may contain additional new paleoclimate information that provides important new constrain on sediment depositional environment and climate. In this case, we examine the geochemical characteristics of the sediments from Alikes Lagoon, Zakynthos island, Western Greece, by calculating enrichment factors for the elements relative to CHS (Clay Shale; Salomons \& Forstner, 1984). The enrichment factor (EF) for any element is given by the following equation:

$$
\mathrm{EF}=\left(\mathrm{C}_{\text {sample }} / \mathrm{C}_{\mathrm{Al} \mathrm{sample}}\right) /\left(\mathrm{C}_{\text {standard }} / \mathrm{C}_{\mathrm{Al} \text { standard }}\right) \text {, }
$$

where $\mathrm{C}_{\text {sample }}$ is the concentration of the element and $\mathrm{C}_{\mathrm{Al} \text { sample }}$ is the concentration of $\mathrm{Al}$ in the sample (Yan et al., 2007). The Al normalization is utilized because concentrations of most elements show correlation with $\mathrm{Al}_{2} \mathrm{O}_{3}$. CSH is used as the standard. Enrichment factor diagrams are shown in Figure 6a-d. 

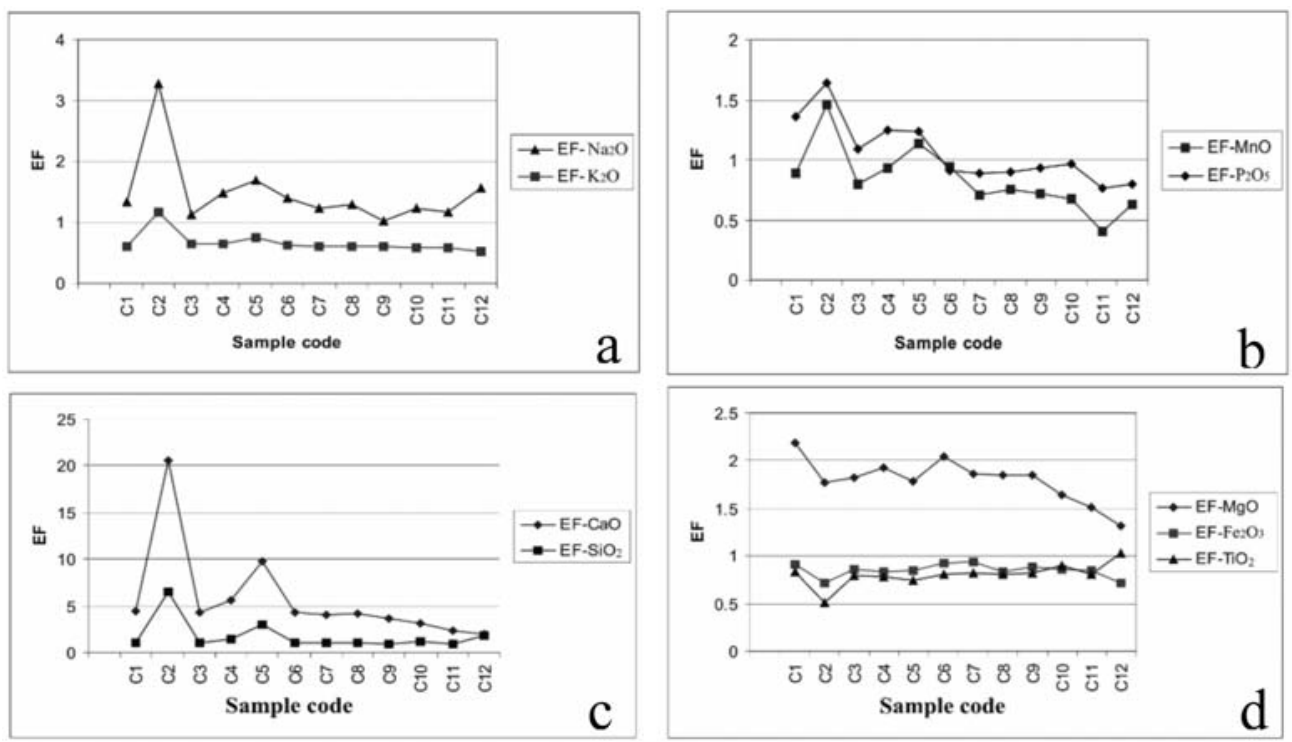

Fig. 6: Element enrichment factor (EF) plot (relative to $\mathrm{CSH}$ ) for the samples from the Alikes Lagoon, Zakynthos island, Western Greece: a) $\mathrm{EF}$ for $\mathrm{K}_{2} \mathrm{O}, \mathrm{Na}_{2} \mathrm{O}$, b) $\mathrm{EF}$ for $\mathrm{MnO}, \mathrm{P}_{2} \mathrm{O}_{5}$, c) $\mathrm{EF}$ for $\mathrm{CaO} . \mathrm{SiO}_{2}$ d) $\mathrm{EF}$ for $\mathrm{MgO}, \mathrm{Fe}_{2} \mathrm{O}_{3}, \mathrm{TiO}_{2}$. (CSH composition from Salomons \& Forstner, 1984).

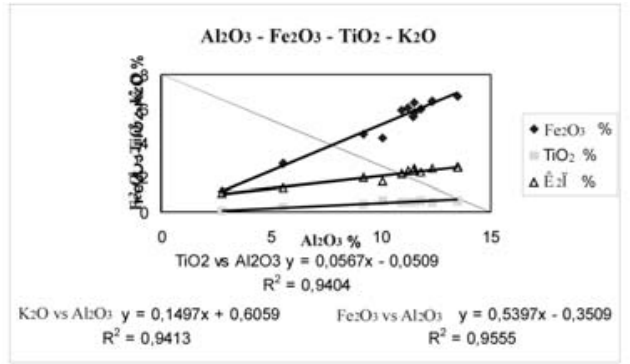

Fig. 7: The $x-y$ plots among $\mathrm{Fe}_{2} \mathrm{O}_{3}, \mathrm{TiO}_{2}, \mathrm{~K}_{2} \mathrm{O}$ and $\mathrm{Al}_{2} \mathrm{O}_{3}$ data from the Alikes Lagoon, Zakynthos island, Western Greece sediments.

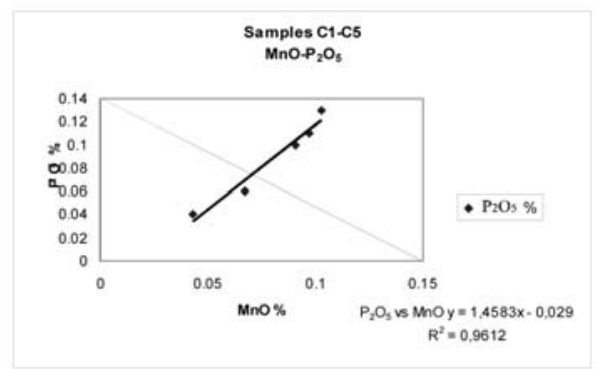

Fig. 8: The $x-y$ plot among $\mathrm{MnO}$ and $\mathrm{P}_{2} \mathrm{O}_{5}$ data from the Alikes Lagoon, Zakynthos island, Western Greece, sediment samples $\mathrm{C} 1-\mathrm{C} 5$.

The samples show that $\mathrm{Na}, \mathrm{Ca}$ and $\mathrm{Mg}$ content are enriched relative to $\mathrm{CSH}$ (Fig. 6a, c and d), while $\mathrm{Mn}$ and $\mathrm{P}$ enrichment factors show variations relative to $\mathrm{CSH}$ (Fig. 6b). K, Fe and Ti enrichment factors show depletion relative to CSH (Fig. 6a and d). Samples C2 and C5 display an abnormally high enrichment factor for $\mathrm{Ca}$, and $\mathrm{Si}$ thus it is possible these data related to the carbonate cementing aggregates, the shell fragments and the presence of quartz and calcite as it is shown from the XRD analysis. By contrast, $\mathrm{Mg}$ enrichment factor for $\mathrm{C} 2$ and $\mathrm{C} 5$ samples having a tendency to degrease due to the lower amounts of chlorite. The same pattern is obvious for Fe and $\mathrm{Ti}$, although their enrichment factors are lower than CSH. It is known that the chemical composition can be influenced by weathering, dissolution and adsorption-desorption processes and these may produce irregular chemical variations in some major and trace elements (Mass and Mc- 
Culloch, 1991). This is consistent with the significant positive linear correlation between $\mathrm{Al}, \mathrm{Fe}$ and Ti classified as a detrital element group, (Al-Fe: $\mathrm{R}^{2}=0.9555$, Al-Ti: $\mathrm{R}^{2}=0.9404$, Fig. 7), while strong positive linear correlation between $\mathrm{Al}$ and $\mathrm{K}\left(\mathrm{R}^{2}=0.9413\right)$, indicating their association with the phyllosilicate fractions such as illite and chlorite (Bauluz et al., 2000), which are present in our samples (Fig. 5).

In the case of $\mathrm{Mg}$, its significant negative linear correlation with $\mathrm{Ca}$ in the horizon extended between $5 \mathrm{~m}$ and $8 \mathrm{~m}$ of the core $\left(\mathrm{R}^{2}=0.988\right)$ implies that this element is consistent with the aluminosilicate fraction.

In addition $\mathrm{Mn}$ is a redox-sensitive element that easily reduced or oxidized by changes of the biogeochemical conditions of the environment (Stumm and Morgan 1996). Mn geochemical behaviour shows differences between $5 \mathrm{~m}$ to $8 \mathrm{~m}$, and $9 \mathrm{~m}$ to $21 \mathrm{~m}$ downcore. In the upper part of the sediment column there is a variation in the Mn enrichment factor relative to CSH, while its significant negative correlation with $\mathrm{Ca}\left(\mathrm{R}^{2}=0.9855\right)$ and the very strong positive correlation with $\mathrm{Al}$ $\left(\mathrm{R}^{2}=0.9678\right)$, indicating $\mathrm{Mn}$ association with the clay fraction and/or oxide-hydroxide phases. In the down part of the sediment core, its depletion compare to CSH (Fig.6b), is compatible with the dissolution of Mn-solid phases due to the presence of abundant organic matter.

The Si enrichment factors (Fig. 6c), together with its significant positive linear correlation with Ca in the upper part of the core $\left(\mathrm{R}^{2}=0.9937\right)$ suggesting the biogenic origin of the element. From $9 \mathrm{~m}$ to $21 \mathrm{~m}$ sediment depth, $\mathrm{Si}$ is mainly associated with the fraction of resistance aluminosilicate minerals, by having a strong negative linear correlation with $\mathrm{Ca}$ and TOC $\left(\mathrm{Ca}-\mathrm{Si}: \mathrm{R}^{2}=0.8324\right.$, TOC-Si: $\mathrm{R}^{2}=$ 0,7362 ). Additionally in the core-top samples, $\mathrm{P}$ is mainly related with manganese oxides/hydroxides phases due to their strong positive linear correlation $\left(\mathrm{R}^{2}=0.9612\right.$, Fig. 8, Yuan-Hui Li et al., 2007).

However, Ti usually behaves as conservative element in a weathering profile, and thus Ti normalized ratios help to track the behaviour of elements during chemical weathering. Additionally chemical weathering affected from environmental changes such as climate and redox conditions (Yan, et. al 2007). Furthermore, the Ti content show no covariance with $\mathrm{SiO}_{2}$ content $\left(\mathrm{R}^{2}=0,2828\right)$ and significant inter-sample variations, hence $\mathrm{Rb}$ and $\mathrm{Cs}$ are normalized to $\mathrm{Ti}$. The $\mathrm{Rb}$ and $\mathrm{Cs}$ are very sensitive to climatic influences and may become leached during chemical weathering. As chemical weathering is largely controlled by moisture and temperature, a wet and warm climate may enhance the chemical weathering (Nesbitt et al., 1980). Variation of $\mathrm{Rb} / \mathrm{Ti}, \mathrm{Cs} / \mathrm{Ti}$ ratios, $\mathrm{CaCO}_{3}$ contents and TOC values imply a warm and wet climate which result in greater vegetation cover (Yan et al., 2007).

\section{Conclusions}

Although the sediment chemical properties variation, can be related to different sediment sources, the rich $\mathrm{Ca}$ and $\mathrm{Si}$ content of the samples indicate high primary production rates during deposition in the past. The higher rate of sedimentation in the Alikes lagoon until mid-Holocene from $5.3 \mathrm{~mm} / \mathrm{yr}$ to $1.03 \mathrm{~mm} / \mathrm{yr}$ in modern times, the grain size statistical parameters, the silt beds and the low sand content of the sediment samples analyzed, suggesting a warm, sheltered muddy tidal flat and/or marshy coastal deposition environments. The grain size statistical parameters, suggests a coastal environment (restricted-shallow) with reduced salinity such as a lagoon margin and in a tidal flat and/or marsh particularly. Depositional environment and the source material affecting the geochemical signature indicating that $\mathrm{Al}, \mathrm{Mg}$, and $\mathrm{K}$ are mainly associated with the aluminosilicate fraction of the sediments analyzed, while $\mathrm{Ca}$, Si mainly related with the biogenic fraction of the sediments in the core top samples. Iron and Ti classified as a detrital element group, while the P and Mn correlation in the top core samples showing its relation with manganese oxides/hydroxides phases. 


\section{References}

Avramidis P. \& Kontopoulos N. 2009. Holocene evolution and sedimentation rate of Alikes Lagoon, Zakynthos island, Western Greece. Preliminary Results, eEarth 4, 23-29.

Avramidis P., Bouzos D., Antoniou V. \& Kontopoulos N. 2008. Application of grain size trend analysis and spatio-temporal changes of sedimentation, as a tool for lagoon management. Case study: the Kotychi lagoon (western Greece). Geological Carpathica, 59, 3, 261-268.

Bauluz, B., Mayayo, M.J., Fernandez-Nieto, C., \& Lopez, J.M.G., 2000. Geochemistry of Precambrian and Paleozoic siliciclastic rocks from the Iberian Range (NE Spain): implications for source-area weathering, sorting, provenance and tectonic setting. Chemical Geology 168, 135- 150.

Condie, K.C., 1993. Chemical composition and evolution of the upper continental crust: contrasting results from surface samples and shales. Chemical Geology 104, 1-37.

Cullers, R.L., 1994. The controls on the major and trace element variation of shales, siltstones, and sandstones of Pennsylvanian-Permian age from uplifted continental blocks in Colorado to platform sediment in Kansas, USA. Geochimica et Cosmochimica Acta 58, 4955-4972.

Elderfield, H., 1990. Tracers of ocean paleoproductivity and paleochemistry: an introduction. Paleoceanography 5, 711-717.

Engel, M. Knipping, H. Bruckner, M. Kiderlen, \& J.C. Kraft 2009. Reconstructing middle to late Holocene palaeogeographies of the lower Messenian plain (southwestern Peloponnese, Greece): Coastline migration, vegetation history and sea level change. Pal. Pal. Pal., 284, (3-4), 257-270.

Folk, R.I. 1974. Petrology of sedimentary rocks. Hamphill, Austin, Texas, 1-182.

Fralick, P.W., Kronberg, B.I., 1997. Geochemical discrimination of clastic sedimentary rock sources. Sedimentary Geology 113, $111-124$.

Gaudette H., Flight W., Toner L., Folger D. 1974. An inexpensive titration method for the determination of organic carbon in recent sediments. J. Sediment. Petrol. 44, 249-253.

Kontopoulos N., \& Avramidis P. 2003. A late Holocene record of environmental changes from the Aliki lagoon, Egion, North Peloponnesus, Greece. Quaternary International, 111, 75-90, 2003.

Kontopoulos N., \& Koutsios A. 2009. A late Holocene record of environmental changes from Kotihi lagoon, Elis Northwest Peloponnesus, Greece. Quaternary International, (in press).

Mass, R., McCulloch, M.T., 1991. The provenance of Archaean clastic metasediments in the Narryer gneiss complex. Western Australia: trace element geochemistry, $\mathrm{Nd}$ isotopes, and $\mathrm{U}-\mathrm{Pb}$ ages for detrital zircons. Geochimica et Cosmochimica Acta 5, 1915-1932.

Nesbitt, H.W., Markovics, G., Price, R.C., 1980. Chemical processes affecting alkalis and alkaline earths during continental weathering. Geochimica et Cosmochimica Acta 44: 1659-1666.

Riley JP, Chester R (1983). Chemical oceanography. Academic, London.

Salomons, W. \& Forstner, U. 1984. Metals in the hydrocycle. Springer- Verlag, Berlin-Heidelberg, p. 349.

Scott, D.B. Piper, D.J.W., \& Panagos A.G. 1979 Recent salt march and intertidal mudflat foraminifera from the western coast of Greece. Riv. Ital. Paleont., 85, 1, 243-266.

Stumm W, Morgan JJ (1996) Aquatic chemistry 3rd edn. Wiley Interscience, New York.

Vött, A. 2007. Relative sea level changes and regional tectonic evolution of seven coastal areas in NW Greece since the mid-Holocene. Quaternary Sciences Review, 26, 894-919.

Yan Yi, Bin Xia, Ge Lin, Xuejun Cui, Xiaoqiong Hu, Pin Yan, \& Faqiang Zhang 2007. Geochemistry of the sedimentary rocks from the Nanxiong Basin, South China and implications for provenance, paleoenvironment and paleoclimate at the K/T boundary. Sedimentary Geology 197 127-140.

Yuan-Hui Li, Takejiro Takamatsu, Yoshiki Sohrin 2007. Geochemistry of Lake Biwa sediments revisited. Limnology 8, 321-330.

Zelilidis, A., Kontopoulos, N, Avramidis, P., \& Piper D.J.W. 1998. Tectonic and sedimentological evolution of the Pliocene - Quaternary basins of Zakynthos, Greece: Case study of the transition from compressional to extensional tectonics, Basin Research, 10, 393-408. 